\title{
PROCESSO ALTERNATIVO PARA REMOÇÃo DE COBRE (II) E NÍQUEL (II) DE SOLUÇÕES AQUOSAS UTILIZANDO CÁPSULAS DE QUITOSANA - ÁlCOOL POLIVINÍlico.
}

\author{
Antoninho Valentini, Mauro C. M. Laranjeira, Simone Fiori, Valfredo T. de Fávere \\ Departamento de Química - UFSC - Trindade - 88040-900 - Florianópolis - SC \\ Marilene Klug \\ Universidade do Sul de Santa Catarina - UNISUL. Av. José Acácio Moreira, 787, 88704-900 Tubarão - SC
}

Recebido em 14/7/98; aceito em 16/8/99

\begin{abstract}
ALTERNATIVE PROCESS FOR REMOVAL OF COPPER AND NICKEL IN AQUEOUS SOLUTIONS, USING CHITOSAN - POLY(VINYL ALCOHOL) CAPSULES. Capsules were prepared from chitosan (QTS)-poly(vinyl alcohol) (PVA) blend by saline coacervation and then by formalization. A adsorbent based on chitosan, insoluble on acid solution, was obtained. The morphology, average diameters of QTS/PVA capsules and their pores were studied by using scanning electron microscopy. The entrapment-adsorption of dimethylglioxime and ethylenediaminetetracetate by the capsules were studied. The removal of the ion nickel (II) and copper (II), was more effective than by using unloaded capsules.
\end{abstract}

Keywords: chitosan; adsorption; capsules.

\section{INTRODUÇÃO}

O conhecimento do equilíbrio de adsorção representa o primeiro passo para investigar as possibilidades de uso de um adsorvente em um determinado processo de separação. Biopolímeros isolados de organismos marinhos são uma nova classe de adsorventes de baixo custo, benignos ao meio ambiente e exibem uma alta especificidade em relação aos íons metáli$\cos ^{1}$. A quitosana, um biopolímero derivado da quitina, possui habilidade para formar complexos com íons de metais de transição devido a presença de grupos amino da unidade 2-amino2-desoxi-D-glicose. A observação de que a quitosana possui uma afinidade por todos os íons metálicos do grupo III, cátions de metais de transição em concentrações na faixa de 20-40 ppm é bem conhecida (Muzzarelli, 1973², 1977³, Masri et al. $1974^{4}$ ). Atualmente encontram-se muitos trabalhos em que se utiliza quitina, quitosana e quitosana modificada quimicamente para a complexação com íons metálicos ${ }^{5-11}$. Quitosana é usualmente obtida na forma de flocos ou em pó, ambos não possuem uma porosidade elevada, e são solúveis em meio ácido, esta solubilidade da quitosana em meio ácido limita seu uso na recuperação de íons metálicos de águas residuais a baixos pHs, como por exemplo águas provenientes de regiões de mineração, (Masri et al, 1978) ${ }^{12}$.

O primeiro desenvolvimento de cápsulas porosas de quitosana sem reticulação com aplicações biomédicas foi reportado por Bodmeier (1989) ${ }^{13}$, que verificou que secando a frio partículas de gel de quitosana, produz-se uma matriz altamente porosa que se dissolve facilmente em solução ácida.

A preparação de cápsulas de quitosana, melhora a resistência química, aumenta a força mecânica e a resistência à abrasão tornando o adsorvente conveniente para o uso em colunas cromatográficas ${ }^{1}$.

A adsorção de agentes complexantes tais como, ácido etilenodiaminotetracético (EDTA) e dimetilglioxima (DMG) em resinas tem sido empregada por muitos autores devido a forte propriedade complexante com os íons metálicos ${ }^{14,15}$.

Objetiva-se neste trabalho a preparação de cápsulas de quitosana-PVA que sejam insolúveis em soluções ácidas, e posterior

mklug@unisul.rct-sc.br adsorção de EDTA e DMG nas mesmas para a complexação com $\mathrm{Cu}(\mathrm{II})$ e $\mathrm{Ni}$ (II) respectivamente, para com isto aumentar sua capacidade de retenção de íons de metais pesados.

\section{EXPERIMENTAL}

Reagentes: A quitosana foi sintetizada baseado no método de Fujita $^{3}$, com algumas modificações, a partir da quitina fornecida pela empresa Kito Química Fina Ltda. Fez-se a hidrólise alcalina da quitina com hidróxido de sódio comercial a $50 \%$, em refluxo durante 3 horas. O processo foi repetido por três vezes, e então o material foi lavado com água até $\mathrm{pH}$ neutro. A seguir o polímero foi dissolvido em ácido acético a $3 \%$, filtrado, e reprecipitado com solução de hidróxido de sódio $1 \mathrm{M}$, para sua purificação; sendo lavado com água até a neutralização e seco em estufa a $60,0^{\circ} \mathrm{C}$. A seguir a quitosana foi moída em moinho de bolas e peneirada, utilizando-se peneira com malha de 75 mesh.

Todos os demais reagentes utilizados possuíam grau analítico.

Blenda: Dissolveu-se 0,75 g de quitosana em 50,0 mL de ácido acético $3 \%$, sob aquecimento brando e agitação constante. Separadamente dissolveu-se 6,80 g de PVA em 50,0 mL de água destilada, sob agitação constante.

A seguir misturou-se as soluções de QTS e PVA, obtendose a blenda polimérica ${ }^{16}$.

Preparação das Cápsulas: Utilizou-se do método de coacervação salina para o preparo das cápsulas. O método consiste em gotejar a blenda anteriormente citada, na solução coagulante, a temperatura de $50 \pm 0,5^{\circ} \mathrm{C}$ sob agitação constante. O sistema foi mantido nestas condições durante trinta minutos. A seguir as cápsulas foram transferidas para a solução formalizante, a temperatura de $60 \pm 0,5^{\circ} \mathrm{C}$ sob agitação constante, durante 30 minutos, (não variou-se o tempo de coagulação e de formalização na obtenção das cápsulas para a realização deste experimento). Posteriormente as cápsulas foram lavadas até $\mathrm{pH}$ neutro, e secas a temperatura ambiente.

Adsorção: A adsorção foi realizada colocando-se aproximadamente $30,0 \mathrm{mg}$ de cápsulas em contato com $25,0 \mathrm{~mL}$ da solução do complexante, (concentração de DMG para cinética foi de 0,0500 mol.dm ${ }^{-3}$, para isotermas entre 0,0100 e 0,1000 mol.dm ${ }^{-3}$; concentração de EDTA para cinética foi de 0,0250 mol.dm ${ }^{-3}$, para isotermas entre 0,0001 e $\left.0,0100 \mathrm{~mol} . \mathrm{dm}^{-3}\right)$, em 
diferentes temperaturas, sob agitação em um sistema de batelada. Os tempos de contato para adsorção, variaram para a cinética, entre zero e vinte e quatro horas, e para as isotermas o tempo de contato com a solução do adsorvente foi de três horas.

A seguir as cápsulas adsorvidas com o complexante foram colocadas em contato com $25,0 \mathrm{~mL}$ de solução de $\mathrm{Ni}$ (II) a pH $=9$, ou $\mathrm{Cu}$ (II) a $\mathrm{pH}=5\left(100,0 \mathrm{mg} \cdot \mathrm{L}^{-1}\right)$ a temperatura ambiente com agitação constante durante noventa minutos. $\mathrm{O}$ controle do $\mathrm{pH}$ foi realizado somente para a complexação com o íon metálico, e não para a adsorção do complexante. A quantidade de íon metálico retido pelas cápsulas foi determinada por espectrometria de absorção atômica; cuja análise foi feita a partir da solução obtida após a digestão das cápsulas contendo o complexo. A análise do íon metálico é mais acessível que a análise do complexante.

\section{RESULTADOS}

\section{Grau de Desacetilação}

A determinação do grau de desacetilação da quitosana realizou-se pelo método de titulação potenciométrica proposta por Broussignac $^{17}$, obtendo-se $77 \%$.

\section{Adsorção}

Cinética de Adsorção: A quantidade de complexante adsorvido foi determinada indiretamente; como a estequiometria do complexo é bem conhecida, é possível determinar a quantidade de ligante que foi adsorvido a partir da quantidade de metal presente na amostra.

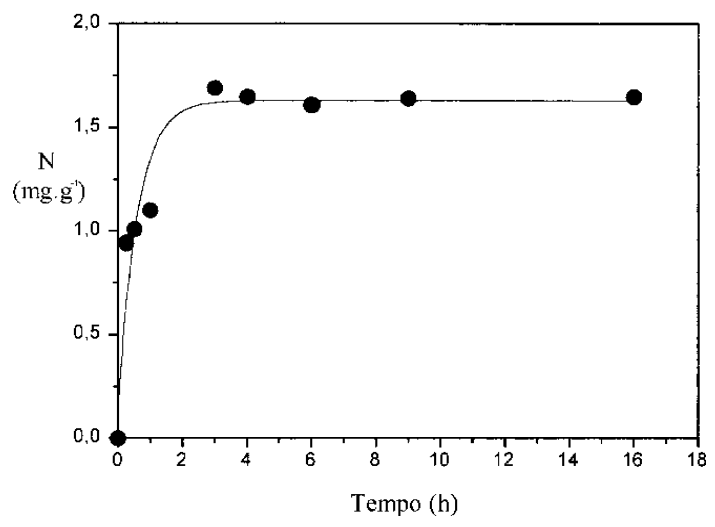

Figura 1. Cinética de adsorção de Ni(II), das cápsulas adsorvidas com DMG; $\left(N=\right.$ massa de Ni(II).massa de cápsulas $\left.^{-1}\right)$.

A Figura 1 mostra a cinética da adsorção da DMG na superfície da cápsula em função do tempo. É observada uma rápida adsorção nos primeiros minutos, seguida por um gradual equilíbrio. O tempo necessário para atingir o equilíbrio de adsorção é de aproximadamente três horas.

Comportamento semelhante é observado para a adsorção de EDTA, representado na Figura 2.

Isoterma de Adsorção: Nas Figuras 3 e 4 tem-se as isotermas de adsorção para o DMG e EDTA, respectivamente, em diferentes temperaturas, onde é possível observar a influência da temperatura no processo de adsorção.

Para o ajuste dos resultados experimentais de adsorção foi utilizado o modelo de isoterma de Langmuir, que apresenta grande flexibilidade para ajustar os dados, e a qual pode ser expressa, na sua forma linear, pela equação 1 :

$\frac{1}{[N]}=\frac{1}{K[S] N_{o}}+\frac{1}{N_{o}}$

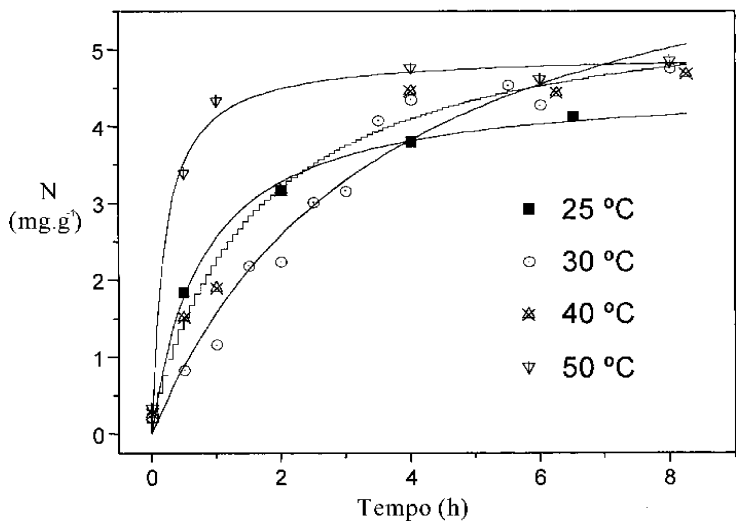

Figura 2. Cinética de adsorção de Cu(II), das cápsulas adsorvidas com EDTA; $\left(N=\right.$ massa de Cu(II).massa de cápsulas $\left.{ }^{-1}\right)$.

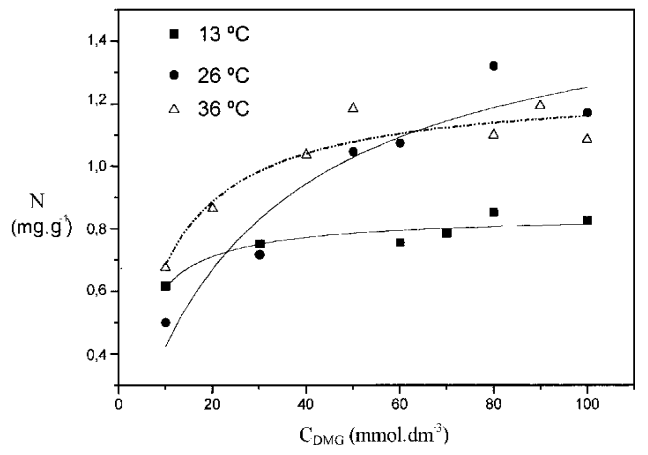

Figura 3. Isoterma de adsorção de Ni(II), das cápsulas adsorvidas com DMG; $\left(N=\right.$ massa de Ni(II).massa de cápsulas $\left.{ }^{-1}\right)$.

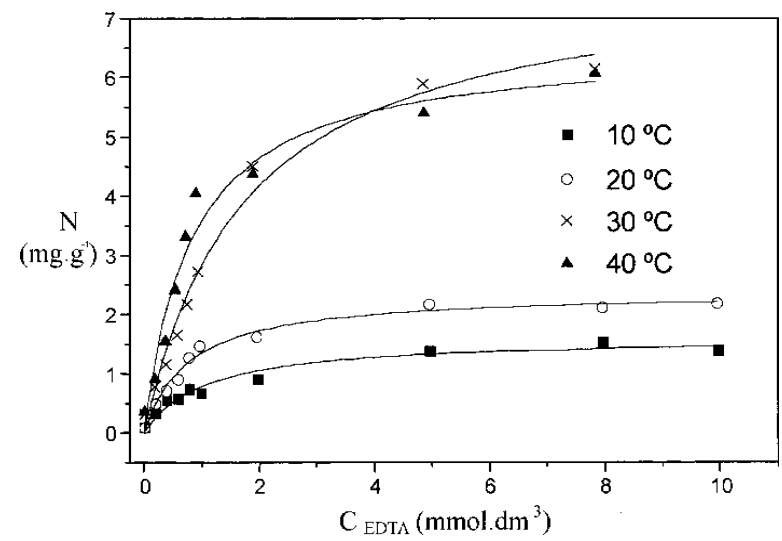

Figura 4. Isoterma de adsorção de Cu(II), das cápsulas adsorvidas com EDTA; ( $N=$ massa de Cu(II).massa de cápsulas $\left.{ }^{-1}\right)$.

Onde [N] representa a quantidade de substrato adsorvido $\left(\mathrm{mg} \cdot \mathrm{g}^{-1}\right) ;[\mathrm{S}]$ é a concentração do substrato, (DMG ou EDTA) $\left(\mathrm{mg} \cdot \mathrm{dm}^{-3}\right) ; N_{o}$ é a capacidade máxima de adsorção $\left(\mathrm{mg} \cdot \mathrm{g}^{-1}\right) ; \mathrm{K}$ é a constante de equilíbrio de adsorção $\left(\mathrm{dm}^{3} \cdot \mathrm{mg}^{-1}\right)$.

Utilizando-se da equação acima para os dados obtidos nas isotermas de adsorção, e calculando-se a capacidade máxima de adsorção pelas cápsulas, observa-se uma significativa variação na quantidade máxima adsorvida. No entanto pela equação observa-se valores questionáveis para a capacidade máxima de adsorção quando comparado com a curva experimental, por este motivo optou-se por obter valores estimados da capacidade máxima de adsorção através das isotermas, cujos valores estimados encontram-se nas Figuras 5 e 6. 


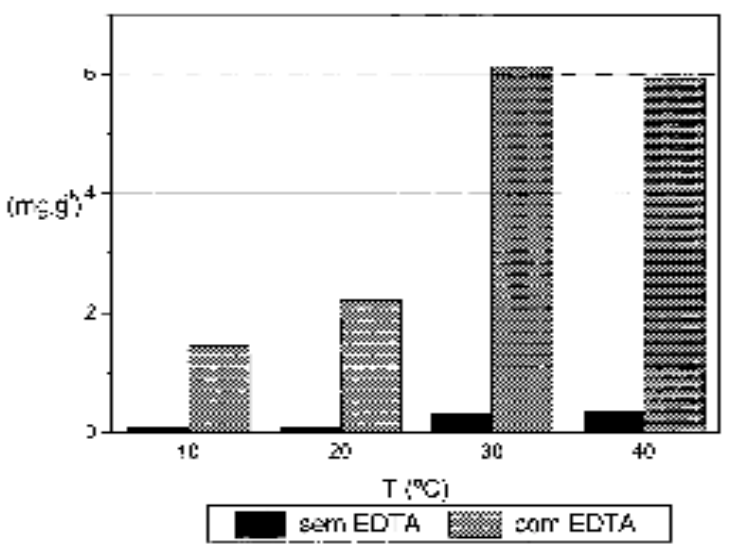

Figura 5. Capacidade máxima de adsorção de Cu(II), para as cápsulas adsorvidas, com e sem EDTA.

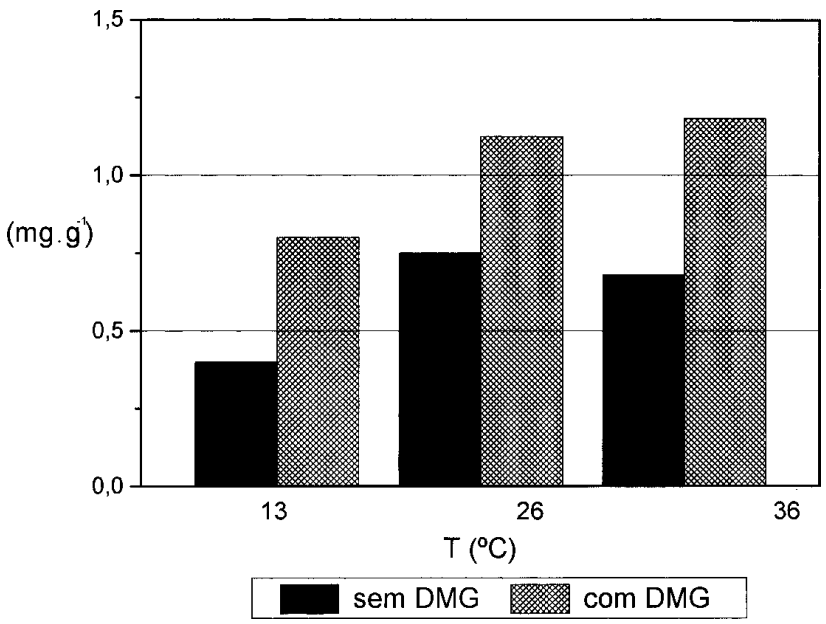

Figura 6. Capacidade máxima de adsorção de Ni(II), para as cápsulas adsorvidas, com e sem DMG.

Através da linearização das isotermas determinou-se o calor de adsorção $(\Delta \mathrm{H})$ envolvido no processo; o valor encontrado foi de - 6,90 Kcal.mol ${ }^{-1}$ e - 6,16 Kcal.mol ${ }^{-1}$, para a adsorção de DMG e EDTA respectivamente, indicando tratar-se de adsorção física.

Dessorção da dimetilglioxima: Com o objetivo de reutilizar as cápsulas após a complexação com o mesmo ligante ou com outro, realizou-se um ensaio qualitativo da dessorção da DMG. As cápsulas anteriormente adsorvidas foram colocadas em contato com etanol variando-se o tempo de contato sob agitação constante a temperatura ambiente. Após, as cápsulas foram postas em contato com solução de $\mathrm{Ni}$ (II), e a quantidade de metal adsorvido pelas cápsulas foi determinada. A Figura 7 representada a seguir nos mostra a dessorção da DMG, e observa-se que a mesma ocorre em um tempo relativamente curto, em aproximadamente três horas todo o ligante é dessorvido, o que nos proporciona a reutilização das cápsulas. A quantidade de $\mathrm{Ni}(\mathrm{II})$ adsorvida pelas cápsulas após este tempo é igual àquela adsorvida pelas cápsulas sem ligante.

Os ciclos de adsorção e dessorção tiveram a mesma eficiência durante cinco vezes, e após este ciclo as cápsulas apresentaram perda de parte da eficiência, podendo ainda serem reutilizadas.

\section{Análises de Microscopia Eletrônica de Varredura (MEV)}

Estrutura porosa das cápsulas: As cápsulas foram analisadas por MEV (microanálise por energia dispersiva EDS, aparelho usado foi SEM - XL30 da Philips, tensão de $20 \mathrm{kV}$, sem padrão) para observar o diâmetro dos poros, sua uniformidade, a espessura da parede e o diâmetro das cápsulas. Para se determinar estes fatores quarenta cápsulas foram analisadas e o resultado obtido é o valor médio das medidas. A Figura 8 mostra a cápsula secionada transversalmente onde é possível observar que seu interior é um espaço vazio e por intermédio da mesma determinarmos a espessura da parede. Por este motivo as cápsulas podem ser utilizadas não só para o estudo de adsorção como também no processo de encapsulação. Foi determinado que o valor médio da espessura da parede é de $350 \mu \mathrm{m}$, e o diâmetro médio interno da cápsula de $690 \mu \mathrm{m}$.

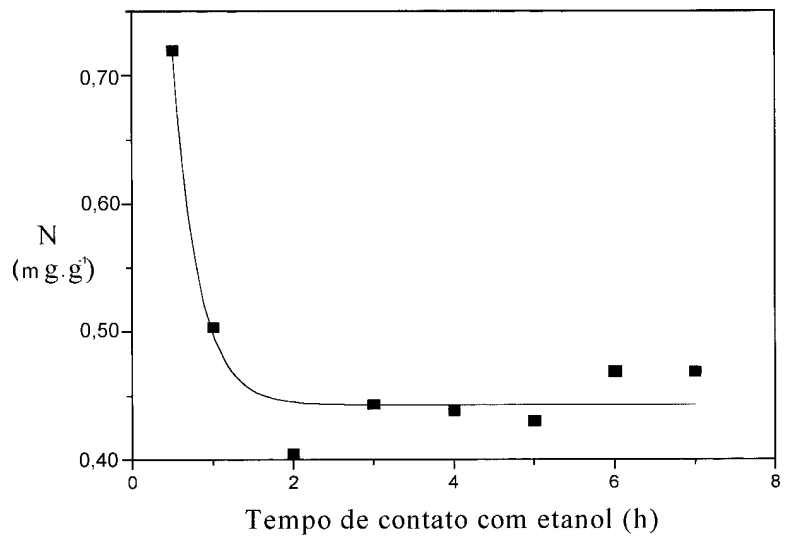

Figura 7. Dessorção de DMG em etanol; ( $N=$ massa de Ni(II).massa de cápsulas $^{-1}$ ).

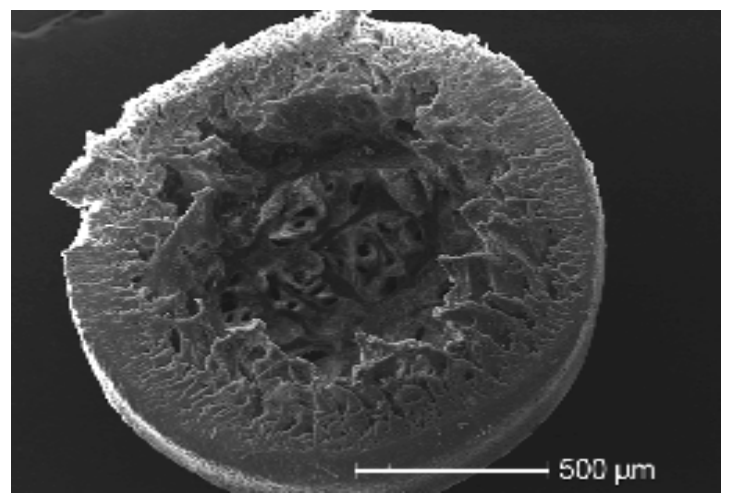

Figura 8. Micrografia da cápsula secionada transversalmente.

Tamanho dos poros externos: A Figura 9 mostra a parede da cápsula onde podemos observar que os poros são relativamente uniformes. $\mathrm{O}$ diâmetro médio dos mesmos foi estimado em $204 \mathrm{~nm}$. Observa-se que existem alguns macroporos na parede da cápsula, sendo que o diâmetro médio destes está situado na faixa de 10,0 a 15,0 microns.

Diâmetro das Cápsulas: A Figura 10 mostra uma cápsula inteira. Observamos que a maioria das cápsulas apresenta um diâmetro externo médio de $1,80 \mathrm{~mm}$, no entanto algumas cápsulas são menores sendo seu diâmetro de $1,30 \mathrm{~mm}$ e outras são maiores apresentando um diâmetro de $2,00 \mathrm{~mm}$.

Por MEV verificou-se que não há formação de complexo no interior da cápsula, (Figura 11) mas somente na superfície externa, e pela mesma técnica verificou-se que não havia Ni adsorvido pela quitosana no interior das cápsulas; o que nos leva a crer que se trata de uma simples adsorção na superfície da mesma. Este fato também foi observado por Maruca e colaboradores em $1982^{7}$, quando realizaram estudos de adsorção do $\mathrm{Cr}$ (III) com quitosana em flocos onde o metal adsorve preferencialmente na superfície externa do polímero. A simples adsorção na superfície da cápsula de QTS/PVA, comprovada pelo baixo valor da entalpia de adsorção do complexante (DMG e EDTA), típico de interações físicas, pode justificar a ausência do íon metálico no 


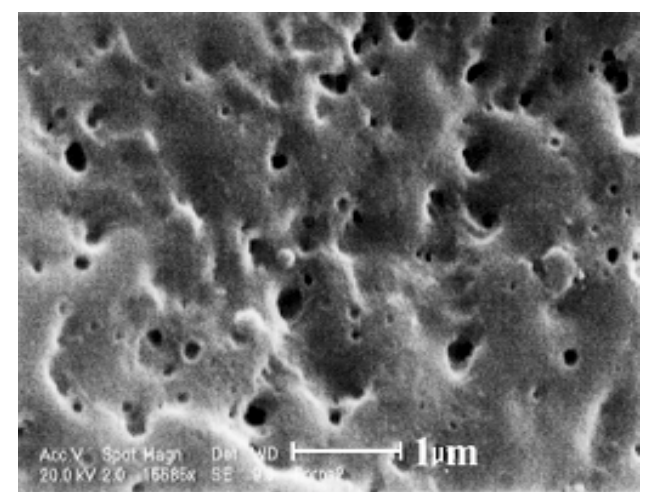

(a)

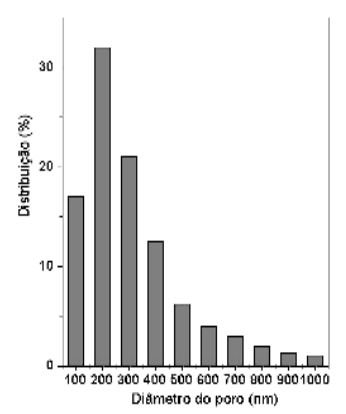

(b)

Figura 9. Micrografia da parede externa da cápsula para visualização dos poros.

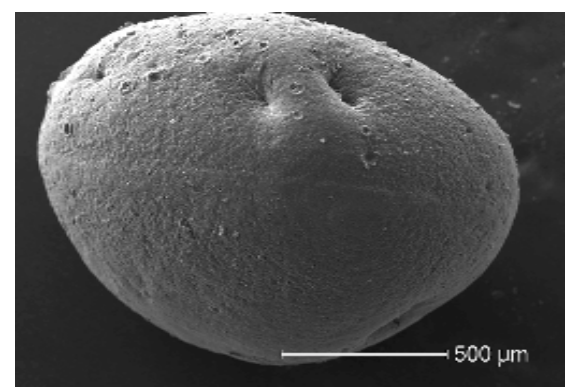

Figura 10. Micrografia da cápsula inteira.

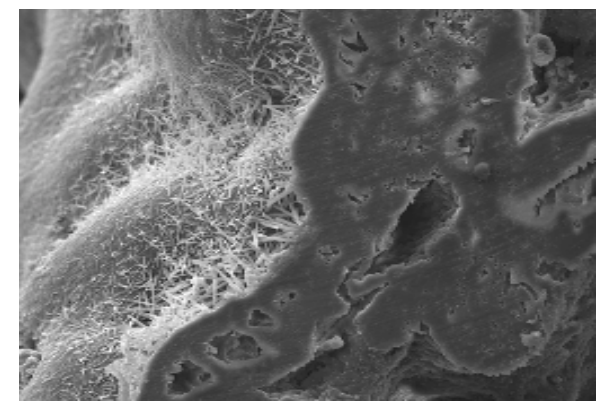

Figura 11. Micrografia da seção transversal da cápsula com o complexo $\mathrm{Ni}(\mathrm{DMG})_{2}$ interior das mesmas. Esta afinidade relativamente baixa do íon metálico pela parede da cápsula é evidenciada pela observação de que na ausência de complexante tem-se um valor muito menor da quantidade adsorvida, que varia de duas a dezoito vezes.

\section{CONCLUSÃO}

Observamos que é viável e efetiva a adsorção dos agentes complexantes, aumentando a capacidade de retenção do metal pela cápsula. $\mathrm{O}$ valor obtido para a retenção do metal $\mathrm{Ni}$ (II) nas cápsulas após a adsorção da DMG é duas vezes maior; para o caso do $\mathrm{Cu}$ (II) observamos que a capacidade de adsorção aumentou em cerca de dezoito vezes, após a adsorção de EDTA. Os agentes complexantes adsorvidos sobre as cápsulas apresentam a vantagem de poderem ser facilmente dessorvidos quando da eluição do metal da coluna, favorecendo o processo de reutilização das cápsulas.

A insolubilidade das cápsulas em meio ácido também foi observada, sendo portanto possível sua utilização em $\mathrm{pH}$ no qual previamente o polímero quitosana era solúvel.

\section{AGRADECIMENTO}

CNPq - Conselho Nacional de Desenvolvimento Científico e Tecnológico.

\section{REFERÊNCIAS}

1. Rorrer, G. L.; Hsien, T.-Y.; American Chem. Society, Ind. Eng. Chem. Res. 1993, 32, 2170.

2. Muzzarelli, R. A. A.; Natural Chelating Polymers; Pergamon Press: New York, 1973.

3. Muzzarelli, R. A. A.; Chitin; Pergamon Press: New York, 1977.

4. Masri, M. S.; Reuter, F. W.; Friedman, M.; J. Appl. Polym. Sci. 1974, 18, 675.

5. McKay, G.; Blair, H. S.; Hindon, A.; Indian J. Chem. 1989, 28A, 356

6. Jha, I. N.; Iyengar, L., Rao, A. V. S.; J. Environ. Eng. 1988, 114, 962

7. Maruca, R.; Suder, B. J.; Wightman, J. P.; J. Appl. Polym. Sci. 1982, 27, 4827.

8. Tong, P.; Baba, Y.; Kawazu. K.; Chem. Lett. 1991, 1529.

9. Randall, J. M.; Randall, V. G.; McDonald, G. M.; Young,R. N.; Masri, M. S.; J. Appl. Polym. Sci. 1979, 23, 727.

10. Peniche, C.; Alvarez, L. W.; Arguelles, W.; J. Appl. Polym. Sci, 1992, 46, 1147.

11. Muzzarelli, R. A. A.; Weckx, M.; Filippini, O.; Carbohidr. Polym. 1989, 11, 293.

12. Masri, M. S.; Randall, V. G.; Pittman, A. G.; J. Am. Chem. Soc., Div. Polym. Chem. 1978, 19, 483.

13. Bodmeier, R.; Oh, K. H.; Pramar, Y.; Preparation and Evaluation of Drug-Containing Chitosan Beads. Drug Develop. Ind. Pharm. 1989, 15, p. 1475- 1494.

14. Dung, Pham Ie; Milas, M. I; Rinaudo, M. \& Desbrières; Carbohydr. Polym., 1994, 24, 209.

15. Torre, M.; Marina, M. L.; Critical Reviews in Analytical Chemistry 1994, 24, 327.

16. Miguez, M. J. B.; Tese de Doutorado; Departamento de Química, UFSC, S. Catarina, 1997

17. Broussignac, J.; Chim. Id. Gén. Chim. 1970, 99, 1241. 